\title{
Survey on Influence Factors for Family Education of Primary and Secondary School Students in Minority Areas of Northern Guangdong
}

\author{
Jianlan Wang, Xianglan Mu, Chenglin Zhang, Suqun Liao, Lina Zhang \\ Shaoguan University, Shaoguan, 512005, China
}

Keywords: northern Guangdong, minority areas, primary and secondary school students, family education, influence factor

\begin{abstract}
The research group made a survey on 11 schools in minority areas of northern Guangdong. In the questionnaire survey, totally 2,231 students from primary and secondary school are involved. According to the survey result, learning environment \& resources of a family, educational background of parents and absence of family members will have an effect on students' growth and learning.

Family is the first school for a child, and parents are first teachers of the child. Family has a direct effect on students' growth. There are many factors influencing the efficiency of family education. Through a comparative analysis on parents' educational background, the number of family children, absence of family members and other factors, this research explores for main issues and influence factors of family education for primary and secondary school students in minority areas, providing feasible suggestions for educators. In total, the author selects 11 senior middle schools, junior high schools and primary schools in Guangdong Province with dense minorities as survey subjects, including Yao Autonomous County of Ruyuan in Shaoguan City, Shixing County of Shaoguan City, Zhuang and Yao Autonomous Counties of Lianshan in Qingyuan City and Yao Autonomous County of Liannan in Qingyuan City. The method of questionnaire survey is mainly adopted. Questionnaires are composed of closed questions and open questions, mainly of closed ones. In total, 2,231 effective questionnaires are recovered. The number of minority students accounts for $43 \%$ of the total number of investigated students. Data of questionnaires is processed with SPSS software system. All differences in statistical results in this paper refer to significant difference of statistics.
\end{abstract}

\section{Result and Analysis}

Data statistical results of questionnaires are concluded as several dimensions in this paper, such as education and teaching of school, family education and minority culture education. A comparative analysis is made between university degree and non-university degree of parents, between the only child and non-only child, between single parent family and non-single parent family and between left-behind children and non-left behind children. Comparative results according to the three dimensions are described as follows:

(I) Family education and its influence

1. Learning environment and resources of family

Generally speaking, favorable learning environment is one of basic conditions for good studies. General conditions of this survey are shown as follows: the proportions of students having access to separate room \& desk, extracurricular materials, computer and other learning tools are 65.6\%, $41.6 \%$ and $28.8 \%$ respectively. Data in Table 1 reflects students' access to learning environment and resources from family. Students from non-single parent families and one-child families or with university degree of their parents have more space for learning activities than students from single parent families and non-only-child families or with non-university degree of their parents. In other words, they have access to separate rooms and desks. Students from one-child families and with university degree of their parents have more extracurricular materials as well as computers and other learning tools.

Table 1 Comparison of Students’ Family Learning Environment and Resources (Population Percentage) 


\begin{tabular}{|c|c|c|c|c|c|c|}
\hline Comparison & \multicolumn{2}{|c|}{$\begin{array}{c}\text { Access to Separate } \\
\text { Room and Desk }\end{array}$} & \multicolumn{2}{|c|}{$\begin{array}{c}\text { Access to } \\
\text { Extracurricular } \\
\text { Materials }\end{array}$} & \multicolumn{2}{|c|}{$\begin{array}{c}\text { Access to Computer } \\
\text { and Other Learning } \\
\text { Tools }\end{array}$} \\
\hline Single parent family & 54.5 & \multirow{2}{*}{$\begin{array}{l}\mathrm{t}=-2.635 \\
\mathrm{P}=0.008\end{array}$} & & & & \\
\hline Non-single parent family & 63.1 & & & & & \\
\hline The only child & 69.3 & \multirow{2}{*}{$\begin{array}{l}\mathrm{t}=-4.171 \\
\mathrm{P}=0.000\end{array}$} & 52.6 & \multirow{2}{*}{$\begin{array}{l}\mathrm{t}=-7.120 \\
\mathrm{P}=0.000\end{array}$} & 46.2 & \multirow{2}{*}{$\begin{array}{l}\mathrm{t}=-11.275 \\
\mathrm{P}=0.000\end{array}$} \\
\hline Non-only child & 35.5 & & 35.5 & & 21.5 & \\
\hline $\begin{array}{c}\text { University degree of } \\
\text { parents }\end{array}$ & 80 & \multirow{2}{*}{$\begin{array}{l}\mathrm{t}=5.757 \\
\mathrm{P}=0.000\end{array}$} & 64.4 & \multirow{2}{*}{$\begin{array}{l}\mathrm{t}=6.999 \\
\mathrm{P}=0.000\end{array}$} & 63.9 & \multirow{2}{*}{$\begin{array}{l}\mathrm{t}=13.095 \\
\mathrm{P}=0.000\end{array}$} \\
\hline $\begin{array}{c}\text { Non-university degree of } \\
\text { parents }\end{array}$ & 59.7 & & 36.7 & & 23 & \\
\hline $\begin{array}{l}\text { University degree of } \\
\text { mother }\end{array}$ & 79.9 & \multirow{2}{*}{$\begin{array}{l}\mathrm{t}=4.675 \\
\mathrm{P}=0.000\end{array}$} & 67.5 & \multirow{2}{*}{$\begin{array}{l}\mathrm{t}=6.431 \\
\mathrm{P}=0.000\end{array}$} & 65.6 & \multirow{2}{*}{$\begin{array}{l}\mathrm{t}=11.434 \\
\mathrm{P}=0.000\end{array}$} \\
\hline $\begin{array}{c}\text { Non-university degree of } \\
\text { mother }\end{array}$ & 60.4 & & 37.4 & & 24.1 & \\
\hline
\end{tabular}

\section{Educational background objectives}

Students' educational background objectives are perspective learning goals, which manifest as expectations for educational background. The author ever made statistics on the question of "I want to keep on studies till ". According to the result, the proportions of students expecting to study till junior high school, senior high school, junior college, undergraduate degree, master degree and doctor degree are 6\%, 15.4\%, 8.5\%, 34.9\%, 8.6\% and 26.6\% respectively. According to the data analysis in Table 2, students with parents having university degree expect more for bachelor, master and doctor degrees than students with parents having no university degree. Students with parents having higher educational backgrounds will select higher educational background objectives. Students' selection of educational background objectives is closely correlated with their parents' models and stimulations.

Table 2 Comparison of Students' Expectations for Educational Background (Population Percentage)

\begin{tabular}{cccccccc}
\hline Comparison & $\begin{array}{c}\text { Junior } \\
\text { High } \\
\text { School }\end{array}$ & $\begin{array}{c}\text { Senior } \\
\text { High } \\
\text { School }\end{array}$ & $\begin{array}{c}\text { Junior } \\
\text { College }\end{array}$ & $\begin{array}{c}\text { Undergr } \\
\text { aduate }\end{array}$ & Master & Doctor & $\begin{array}{c}\text { T } \\
\text { Inspection }\end{array}$ \\
\hline $\begin{array}{c}\text { University degree } \\
\text { of father }\end{array}$ & 5.2 & 7.2 & 3.1 & 39.4 & 14 & 31.1 & \\
$\begin{array}{c}\text { Non-university } \\
\text { degree of father }\end{array}$ & 6.2 & 16 & 8.8 & 34.8 & 8.2 & 26 & $\begin{array}{r}\mathrm{t}=2.543 \\
\begin{array}{c}\text { University degree } \\
\text { of mother }\end{array}\end{array}$ \\
$\begin{array}{c}\text { Non-university } \\
\text { degree of mother }\end{array}$ & 6.5 & 5.6 & 3.5 & 40.5 & 14.7 & 32.2 & \\
\hline & 15.3 & 8.6 & 35.1 & 8.4 & 26.4 & $\begin{array}{r}\mathrm{t}=2.574 \\
\mathrm{P}=0.010\end{array}$ \\
\hline
\end{tabular}




\section{Happiness and annoyance}

Viewed from students' degree of happiness and annoyance, 28.7\% students think that they are happy, 63.3\% students are happy sometimes, and 8\% students are unhappy. According to data in Table 3, students with their parents having higher educational backgrounds are happier that students with their parents having lower educational backgrounds.

Table 3 Comparison of Students’ Happiness and Annoyance (Population Percentage)

\begin{tabular}{ccccc}
\hline $\begin{array}{c}\text { Comparison } \\
\text { Happy }\end{array}$ & $\begin{array}{c}\text { Very } \\
\text { Sometimes }\end{array}$ & $\begin{array}{c}\text { Happy } \\
\text { Unhappy }\end{array}$ & T Inspection \\
\hline $\begin{array}{c}\text { father } \\
\text { Non-university degree } \\
\text { of father }\end{array}$ & 36.8 & 55.2 & 8 & \\
$\begin{array}{c}\text { University degree of } \\
\text { mother }\end{array}$ & 39.3 & 52.7 & 8.1 & $\begin{array}{c}\mathrm{t}=-2.134 \\
\mathrm{P}=0.033\end{array}$ \\
$\begin{array}{c}\text { Non-university degree } \\
\text { of mother }\end{array}$ & 27.3 & 64.6 & 8.1 & $\mathrm{t}=-2.609$ \\
\end{tabular}

$\mathrm{P} \leq 0.05$ * significant difference

Most students (accounting for 68.6\%) think that their parents care about their happiness and annoyance. The proportions of students who think that their parents sometimes care about and never care about their happiness and annoyance are $24.9 \%$ and $6.5 \%$ respectively. According to relevant data in Table 4, left-behind students and students from single parent families or one-child families seldom feel that their parents "care about their happiness" than non-left-behind students and students from non-single parents families and non-one-child families.

Table 4 Comparison of Students' Opinions on Their Parents' Care about Their Happiness (Population

Percentage)

\begin{tabular}{|c|c|c|c|c|c|}
\hline Comparison & Care & $\begin{array}{c}\text { Care } \\
\text { Sometimes }\end{array}$ & $\begin{array}{l}\text { Don't } \\
\text { Care }\end{array}$ & Others & T Inspection \\
\hline $\begin{array}{l}\text { Single parent } \\
\text { family }\end{array}$ & 62.1 & 25.6 & 11.8 & 0.5 & $t=3.141$ \\
\hline $\begin{array}{c}\text { Non-single } \\
\text { parent family }\end{array}$ & 69.7 & 24.7 & 5.0 & 0.6 & $\mathrm{P}=0.002$ \\
\hline $\begin{array}{l}\text { One-child } \\
\text { family }\end{array}$ & 65.9 & 25.4 & 8.1 & 0.6 & $\mathrm{t}=-2.121$ \\
\hline $\begin{array}{l}\text { Non-one-child } \\
\text { family }\end{array}$ & 69.6 & 24.7 & 5.1 & 0.6 & $\mathrm{P}=0.034$ \\
\hline $\begin{array}{l}\text { Left-behind } \\
\text { children }\end{array}$ & 63.8 & 25.2 & 10.6 & 0.4 & $\mathrm{t}=-2.449$ \\
\hline $\begin{array}{l}\text { Non-left-behind } \\
\text { children }\end{array}$ & 69.3 & 25 & 5.1 & 0.6 & $\mathrm{P}=0.014$ \\
\hline
\end{tabular}

$\mathrm{P} \leq 0.05 *$ significant difference

In terms of factors for students' annoyance, statistical results of questionnaires are described as follows: $80.2 \%$ students select "academic record", and $25.1 \%$ students select "poor family 
conditions". The proportions of students selecting "few friends", "disciplines of parents and teachers", and "unfavorable appearance" are 16.9\%, 16.8\% and 13.4\% respectively. According to comparative results, more students from single parent families and non-one-child families and with their parents having no university degree are annoyed by "poor family conditions" than students from non-single parent families or one-child families and with their parents having university degree. More students from non-one-child families are annoyed by "academic record” than students from one-child families. More students with their parents having university degree are annoyed by "unfavorable appearance" than students with their parents having no university degree. More students with their mothers having university degree are annoyed by "disciplines of parents and teachers" than students with their mothers having no university degree.

(II) Education and teaching about school

Viewed from the results of questionnaires, most students are satisfactory with infrastructures of school. The proportions of students thinking that sports facilities, dorm environment and dining room conditions of school can meet their needs are $88.6 \%, 75.9 \%$ and $69.3 \%$ respectively. Significant difference only lies on lower satisfaction of left-behind students for sports facilities of school than non-left-behind students, namely $19.2 \%$ and $25.1 \%$ respectively ( $\mathrm{t}=-3.093 ; \mathrm{P}=0.002$ ).

For learning of courses, students usually have higher records in courses that they like. Their evaluations about courses that they get higher records are shown in Fig. 1. It is found thought comparison that students with their fathers having university degree get higher scores in English courses than students with their fathers having no university degree, namely $36.1 \%$ and $23.8 \%$ respectively ( $\mathrm{t}=3.903 ; \mathrm{P}=0.000)$. However, students with their mothers having university degree also get higher scores in English courses than students with their mothers having no university degree, namely $37.7 \%$ and $24.1 \%$ respectively $(t=3.680 ; \mathrm{P}=0.000)$.

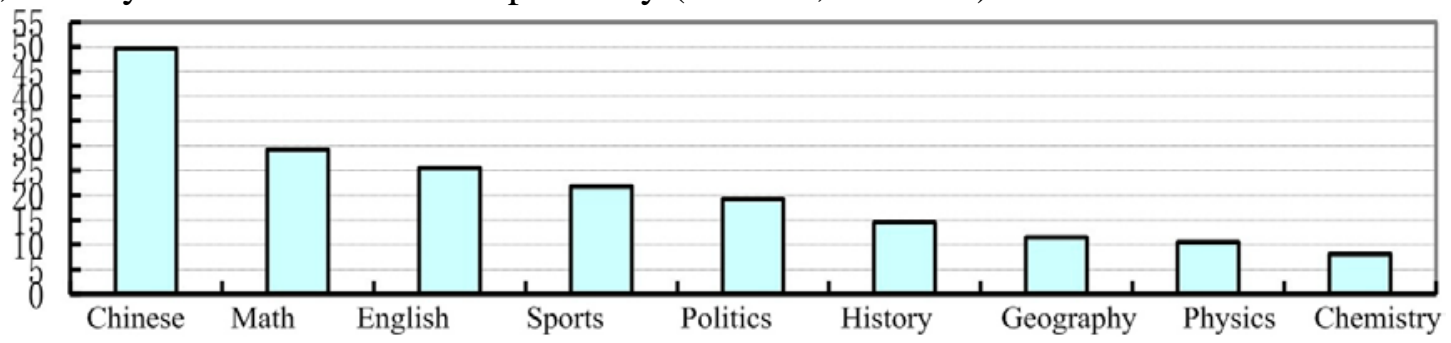

Fig. 1 Courses with Higher Scores

For attributions of successful studies, statistical results of questionnaires are shown in Fig. 2. The results after comparison are described as follows: students from one-child families or single parent families and with their mothers having university degree less emphasize "hardworking" than students from non-one-child families or non-single parent families and with their mothers having no university degree. More students from one-child families and with their parents having university degree think that is resulted from their wisdom than students from non-one-child families and with their parents having no university degree. Students from one-child families and with their mothers having university degree more emphasize "good luck" than students from non-one-child families and with their mothers having no university degree. Students from single parent families more think it is resulted from "teachers' good teaching” than students from non-single parent families. 


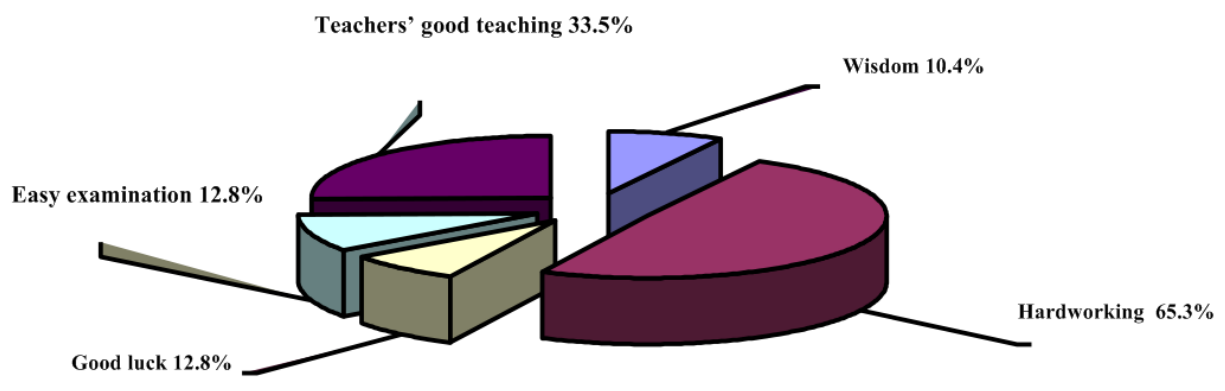

Fig. 2 Attributions of Successful Studies

With respect to interpersonal communication, 92\% students are willing to communicate with teachers. 37.1\% students like to communicate with teachers. Students with their mothers having university degree prefer to communicate with teachers than students with their mothers having no university degree, namely $48.7 \%$ and $35.6 \%$ respectively ( $t=-3.298 ; \mathrm{P}=0.001$ ). $97 \%$ students are willing to communicate with classmates. 92\% students like to communicate with classmates. Generally speaking, students prefer to communicate with peers. When they encounter unhappy things, they also first think of their peers, as shown in detailed in Fig. 3. More students from one-child families or single parent families and with their parents having university degree eliminate their unhappiness through playing when compared with students from non-one-child families or non-single parent families and with their parents having no university degree. The proportions are $18.4 \%, 18.7 \%, 22.4 \%$ and $21.4 \%$ respectively.

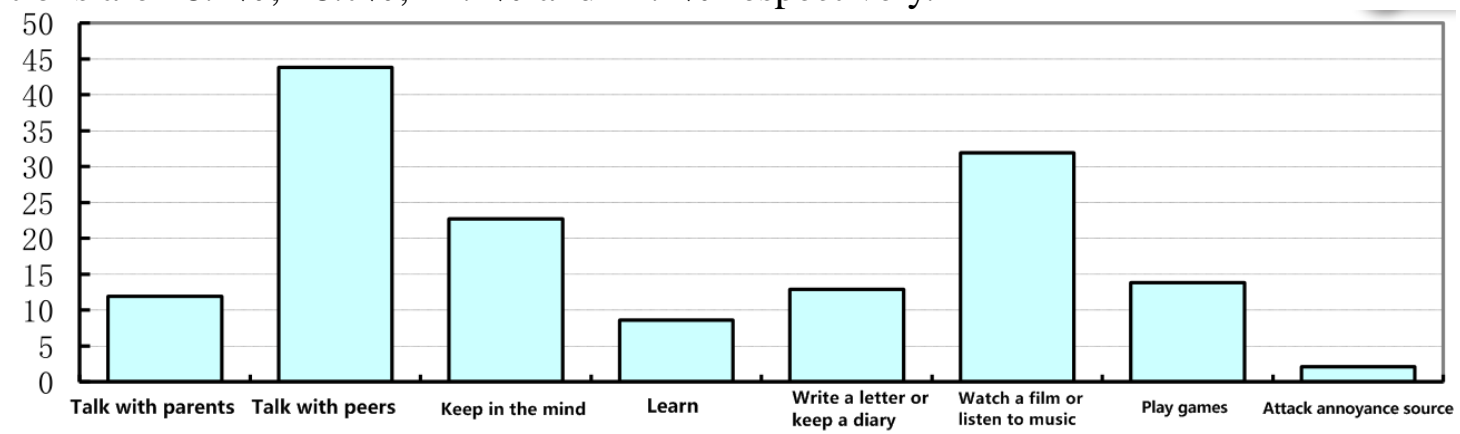

Fig. 3 Students’ Principal Vent Ways for Unhappiness

(III) Cultural education about minorities

Students' acceptance degree of national dresses can reflect inheritance conditions of ethnic culture. According to statistical results of the survey, $70.5 \%$ students understand history and customs of local minorities. 27.9\% students think that local national dresses are "very beautiful". $33.2 \%$ students like to wear national dresses. According to the comparative results, more students from non-one-child families think national dresses are "very beautiful" and "like" to wear national dresses when compared with students from one-child families ( $\mathrm{t}=-2.794 \mathrm{P}=0.005 ; \mathrm{t}=-3.460$ $\mathrm{P}=0.001$ ). Most students from minority families are not the only child in the family. However, minority students prefer national dresses when compared with students from the Han nationality ${ }^{[1]}$. Therefore, more students from non-one-child families think national dresses are "very beautiful" and "like" to wear national dresses when compared with students from one-child families.

Activities with ethnic features are developed in most schools in minorities areas. According to the information from questionnaires, students understand the history and custom of local minorities mainly through the following four ways: i) activities advocated or organized by school; ii) introduction by teachers on class; iii) parents or family life; and television and other media. For detailed information, please refer to Fig. 4. 
Introduction by teachers in class $22.3 \%$

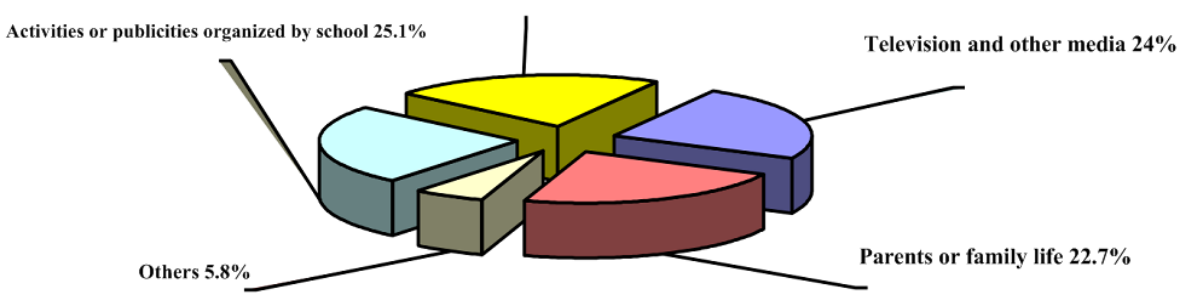

Fig. 4 Main Ways of Students Understanding History and Custom of Local Minorities

It is found through comparison that there is significant difference between students from one-child families and students from non-one-child families, between students with their fathers having university degree and students with their fathers having no university degree, and between students with their mothers having university degree and students with their mothers having no university degree in main ways to understand the history and custom of local minorities, namely $\mathrm{t}=-3.837$ and $\mathrm{P}=0.000 ; \mathrm{t}=2.996$ and $\mathrm{P}=0.003$; and $\mathrm{t}=2.576$ and $\mathrm{P}=0.010$. More students from one-child families and with their parents having university degree understand such information through television and other media, with the proportions as $32.5 \%, 33.6 \%$ and $37.7 \%$ respectively. At the same time, they also understand such information through parents or family life. More students from non-one-child families and with their parents having no university degree understand such information through activities advocated or organized by school. 30.2\% students with their mothers having university degree understand the history and custom of local minorities through "introduction by teachers on class". This proportion is greater than that of students with their mothers having no university degree.

II. Conclusion and Enlightenment

(I) Learning environment and resources of family will have an effect on students' growth and learning.

Undoubtedly, separate space and complete learning tools are included in a favorable family learning environment for students. The way of students' obtaining minority knowledge can reflect the important influence of family ambience on students. More students from one-child families and with their parents having higher educational backgrounds obtain knowledge and information about minorities in the family, which is directly correlated with their favorable family learning resources. For instance, they can use computer to look up relevant information, while other students are mostly or only taught by their teachers on class or obtain relevant knowledge through activities or propagandas organized by school. According to the survey, about $15 \%$ students relieve their negative emotions by playing games. If tools for emotion relief are available in the family, students in need should be timely provided, so as to avoid or reduce their relief in game machine rooms and give parents more opportunities to communicate with their children.

Therefore, parents should try to create a favorable family learning environment and provide computer and other modernized learning tools. Thus, it is not only convenient for their children to mutually enlighten and help with other peers but also beneficial for their children to communicate with their parents. Parents should guide young children to correctly use computer and control the surfing time of children with poor self-discipline, making computer to become a tool promoting children's studies.

(II) Parents' educational background will have an effect on students' growth and learning.

Firstly, it represents at the guidance of learning direction and objective. It is easy for parents with 
university degree to become their children's learning models. Parents' Rosenthal effect makes students with their parents having higher educational backgrounds to expect more to get higher educational backgrounds in the future. The same phenomenon is also represented in another survey made by the author previously. More girls with their parents having university degree select "master degree candidate" and "doctoral candidate" as their academic expectations [2]. Parents having academic life experiences deeply experience the communication function of English in the current society. To walk out of China and face the world, students must lay a solid foundation of foreign languages. Students with their parents having higher educational backgrounds are influenced by what they constantly see and hear, and naturally pay attention to learning of English. Therefore, they get higher scores in English courses.

Secondly, it represents at the guidance of attribution of success and failure. Parents with many experiences in learning success and failure often communicate with their children. As a result, their children express and relieve emotions naturally in most cases. Parents can timely find their children's ideological trends, confusions and unhappiness, and properly persuade and encourage them, making them to have a correct understanding of themselves. With respect to the guidance of attribution of academic success and failure, for instance, success admittedly needs "hardworking", but it also can not be separated from "teachers' good teaching” and "good luck". We should also not deny their "wisdom". Main reasons for failure are "insufficient efforts" and "insufficient carefulness". Students should learn to confidently face success and failure, so as to harvest learning and make progress.

(III) Absence of family members will have an effect on students' growth and learning.

According to the results of this survey, left-behind students are less satisfactory with sports facilities of school, reflecting their higher requirements for sports facilities of school. "Teachers' good teaching" is listed as the principal factor for academic success by students from single parent families. For affirmative answer to "my parents care about my happiness", the number of left-behind students and students from single parent families or one-child families are obviously less than the number of non-left-behind students and students from non-single parent families or non-one-child families. According to this information, left-behind students and students from single parent families and one-child families more need and rely on environmental facilities of school for activity and communication. Additional such students rely more on teachers' education and teaching.

According to the results of this survey, students from one-child families have more special questions when compared with other students. In terms of attributions of academic record, that is also consistent with students with their parents having university degree. This gives educators the following enlightenments: educators and education administrators should transfer the center of work from students from one-child families to left-behind students and students from single parent families, guarantee conditions and facilities for their learning and development in school, care more about them, and allow them to grow healthily.

\section{Acknowledgments}

This paper is one of results belonging to funding projects by Lingnan Education and Research Institute "Survey and Research on Basic Education at Minority Areas of Northern Guangdong" (Project No.: LN2011JC02).

\section{References:}

[1] Wang Jianlan, Zhang Lina, Liao Suqun and others, Current Situation of and Countermeasures for Minority Culture Inheritance in School Education - Survey Based on Minority Areas of

Northern Guangdong, Journal of The Chinese Society of Education, 2014 (4);

[2] Wang Jianlan, Li Jun and Tan Hongxiu, Exploration for Family Influence Factors for Girls in 
Middle School - Survey on Female Middle School Education of Northern Guangdong [J], Journal of Shaoguan University, 2013 (9). 